\title{
Berzosertib (VE-822) inhibits gastric cancer cell proliferation via base excision repair system
}

This article was published in the following Dove Press journal:

Cancer Management and Research

\section{Fubiao $\mathrm{Ni} \mathbb{D}^{1, *}$ \\ Hengjie Tang ${ }^{1} *$ \\ Cheng Wang ${ }^{1} *$ \\ Zixiang Wang ${ }^{2}$ \\ Fangyi $\mathrm{Yu}^{2}$ \\ Bicheng Chen' \\ Linxiao Sun $\mathbb{D}^{\prime}$}

'Key Laboratory of Diagnosis and Treatment of Severe Hepato-Pancreatic Diseases of Zhejiang Province, Zhejiang Provincial Top Key Discipline in Surgery, First Affiliated Hospital of Wenzhou Medical University, Wenzhou, Zhejiang, People's Republic of China; ${ }^{2}$ First College of Clinical Medicine, Wenzhou Medical University, Wenzhou, Zhejiang, People's Republic of China

*These authors contributed equally to this work
Correspondence: Linxiao Sun

Key Laboratory of Diagnosis and

Treatment of Severe Hepato-Pancreatic Diseases of Zhejiang Province, Zhejiang Provincial Top Key Discipline in Surgery, First Affiliated Hospital of Wenzhou Medical University, Fanhai West Road, Nanbaixiang Street, Wenzhou 325006,

Zhejiang, People's Republic of China

Emailsunlinxiao@wmu.edu.cnn
Background: Current investigations suggest that the Base Excision Repair (BER) system may change DNA repair capacity and affect clinical gastric cancer progression such as overall survival. However, the prognostic value of BER system members in gastric cancer remains unclear.

Methods: We explored the prognostic correlation between 7 individual BER genes, including uracil-DNA glycosylase (UNG), Single-strand-selective monofunctional uracil-DNA glycosylase 1 (SMUG1), Methyl-CpG binding domain 4 (MBD4), thymine DNA glycosylase (TDG), 8-oxoguanine DNA glycosylase (OGG1), MutY DNA glycosylase (MUTYH) and Nei like DNA glycosylase 1 (NEIL1), expression and overall survival (OS) in different clinical data, such as Lauren classification, pathological stages, human epidermal growth factor receptor-2 (HER2) expression status, treatment strategy, gender and differentiation degree in gastric cancer patients, using Kaplan-Meier plotter (KM plotter) online database. Based on the bioinformatics analysis, we utilized Berzosertib (VE-822) to inhibit DNA damage repair in cancer cells compared to solvent control group via real-time cellular analysis (RTCA), flow cytometry, colony formation and migration assay. Finally, we utilized reverse transcriptionpolymerase chain reaction (RT-PCR) to confirm the expression of BER members between normal and two gastric cancer cells or solvent and VE-822 treated groups.

Results: Our work revealed that high UNG mRNA expression was correlated with high overall survival probability; however, high SMUG1, MBD4, TDG, OGG1, MUTYH and NEIL1 mRNA expression showed relatively low overall survival probability in all GC patients. Additionally, UNG was associated with high overall survival probability in intestinal and diffuse types, but SMUG1 and NEIL1 showed opposite results. Further, VE-822 pharmacological experiment suggested that inhibition of DNA damage repair suppressed gastric cancer cells' proliferation and migration ability via inducing apoptosis. Further, realtime polymerase chain reaction results proposed the inhibition of gastric cancer cells by VE822 may be through UNG, MUTYH and OGG-1 of BER system.

Conclusion: We comprehensively analyze the prognostic value of the BER system (UNG, SMUG1, MBD4, TDG, OGG1, MUTYH and NEIL1) based on bioinformatics analysis and experimental confirmation. BER members are associated with distinctive prognostic significance and maybe new valuable prognostic indicators in gastric cancer.

Keywords: base excision repair, gastric cancer, Kaplan-Meier plotter

\section{Introduction}

Gastric cancer (GC) is one frequently occurring malignancies and the third leading cause of cancer-related mortalities worldwide. ${ }^{1}$ Though early diagnosis and treatment of gastric cancer detection have been improved in the last decade, the prognosis of gastric cancer remains poor with a median overall survival (OS) of 
12 months. $^{2}$ In clinical, chemoradiotherapy is the most widely used therapies in clinical GC treatment; however, chemoradiotherapy may cause DNA damage in non-cancerous cells leading to tissue toxicity in patients. ${ }^{2,3}$ Although effective therapy and specific medicine for GC is scarce, identification of novel prognostic biomarkers and potential drug therapeutic targets are urgently required in GC diagnosis and treatment. ${ }^{2,3}$

Base excision repair (BER) system involving in repairing lost or mispairing DNA bases is the most prevalent pathway in damaged bases modification. ${ }^{4}$ Imbalance of BER results in the accumulation of DNA damage and is related to multiple cancer malignant transformations including gastric cancer. ${ }^{5}$ The absence of BER increased DNA damage by endogenous reactive oxygen species (ROS) and further resulted in carcinogenesis. ${ }^{5}$ Moreover, BER system was also related to DNA polymorphisms regulation and the false key DNA variant not corrected may be related to cancer risk. ${ }^{6}$ However, the diagnosis and treatment values of BER system in gastric cancer have not been determined.

In our study, we performed a comprehensive KaplanMeier plotter (KM plotter) analysis to demonstrate the relationship between alterations of BER and prognosis of GC patients. However, our results only found uracil-DNA glycosylase (UNG) overexpression was associated with better OS in gastric cancer patients, high expression of single-strand-selective monofunctional uracil-DNA glycosylase 1 (SMUG1), methyl-CpG binding domain 4 (MBD4), thymine DNA glycosylase (TDG), 8-oxoguanine DNA glycosylase (OGG1), MutY DNA glycosylase (MUTYH) and Nei like DNA glycosylase 1 (NEIL1) were correlated with poor OS. Further analysis indicated that UNG was associated with better OS of all patients, intestinal and diffuse gastric cancer, as well as cancer of pathological stages 1 and 3 .

\section{Materials and methods Survival analysis of BER system}

To evaluate the significance and association between individual BER system mRNA levels and OS of gastric cancer patients, an online KM plotter database (http://kmplot.com) was utilized. The 7 selected BER pathway genes including UNG, SMUG1, MBD4, TDG, OGG1, MUTYH and NEIL1 were analyzed. The prognostic roles were estimated based on Lauren classification and clinical outcomes (including pathological stages, human epidermal growth factor receptor-2
(HER2) expression status, treatment strategy, differentiation degree and gender). In the Kaplan-Meier survival plots, the certain gene mRNA expression above or below the median splits the cases into high expression group or low expression group and the number-at-risk is indicated below the main plot. Hazard ratio (HR) and 95\% confidence intervals as well as $\log$ rank $P$-value were calculated and displayed. $P<0.05$ is statistically significant.

\section{Cells and cell culture}

Human gastric cancer cell lines (BGC-823 and MKN-45) were obtained from the American Type Culture Collection (ATCC, Manassas, USA). The cells were cultured in Dulbecco's modified Eagle's medium-high glucose $(4.5 \mathrm{~g} / \mathrm{L})$ with L-Glutamine and sodium pyruvate $(110 \mathrm{mg} / \mathrm{L})$ (Thermo Fisher Scientific, Waltham, USA), containing $10 \%$ fetal bovine serum (Thermo Fisher Scientific, Waltham, USA), and $1 \%$ Penicillin-Streptomycin (Thermo Fisher Scientific, Waltham, USA) and were maintained at $37^{\circ} \mathrm{C}$ in a humidified chamber with $5 \% \mathrm{CO}_{2}$. The medium was changed every 1-2 days.

\section{Regents}

Berzosertib (VE-822) was purchased from Selleck library (Selleck Chemicals, Houston, USA). VE-822 was dissolved in dimethylsulfoxide (DMSO) as $10 \mathrm{mM}$ for stock

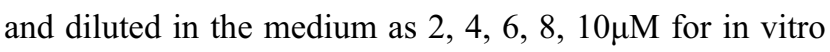
studies compared to $0.1 \%$ DMSO as a solvent control group.

\section{Real-time cellular analysis}

The cells were seeded at $2 \times 10^{5}$ cells per well in cell culture E16-Plate (ACEA Biosciences, San Diego, USA) for proliferation assay and the cell growth index was recorded using Label-free Real-time Cellular Analysis System (RTCA; Roche, Penzberg, Germany) automatically. The cell growth index was normalized at every time point when the cells were treated.

\section{Colony formation assay}

The cells were plated in 6-well plates with 1000-2000 cells per well. When the cells formed visible colonies, 0 , $2,4,6,8,10 \mu \mathrm{M}$ VE-822 was added. After 2 days, colonies were stained with crystal violet and counted.

\section{Migration assay}

The cells were seeded in 6-well plates with 20,0000 cells per well and incubated at $37^{\circ} \mathrm{C}$ for $48 \mathrm{hrs}$. Then, the culture area was scratched with a crystal pipette tip to 
make a linear gap in the confluent cell monolayer. Then, $0.01 \mathrm{M}$ PBS was used to wash the cells 3 times gently and medium with $0,5,10 \mu \mathrm{M}$ VE-822 was added. Cells were allowed to fill the gap and images of the culture area were captured using an inverted microscope every 24 hrs.

\section{Flow-cytometry analysis of apoptosis}

The cells were treated with $0,2,4,6,8,10 \mu \mathrm{M}$ VE- 822 in a 6-well plate $\left(5 \times 10^{5}\right.$ cells $/ \mathrm{mL}, 2 \mathrm{~mL} /$ well $)$, washed with $0.01 \mathrm{M}$ PBS. When the cells confluence reached $85 \%$, the cells were harvested and re-suspended in binding buffer (Thermo Fisher Scientific, Waltham, USA) containing $50 \mathrm{mM}$ HEPES, $700 \mathrm{mM} \mathrm{NaCl}$ and $12.5 \mathrm{mM} \mathrm{CaCl} 2, \mathrm{pH} 7.4$ with a density of $5 \times 10^{5}$ cells $/ \mathrm{mL}$, then incubated with $5 \mu \mathrm{L}$ Annexin V-FITC for $15 \mathrm{~min}$ at room temperature under dark condition, and further incubated with $5 \mu \mathrm{L}$ propidium iodide (PI) for another 5 mins at room temperature under dark condition. Finally, flow-cytometry was performed by utilizing a FACS C6 instrument. The data were analyzed by FlowJo (version 7.6).

\section{RNA isolation and RT-PCR}

Total RNA was isolated from cells by trizol reagent (Thermo Fisher Scientific, Waltham, USA). RNA was then reversetranscribed into cDNA by High Capacity cDNA Reverse Transcription Kit (Thermo Fisher Scientific, Waltham, USA) following the protocol at $37^{\circ} \mathrm{C}$ for 60 mins. Then, reverse transcriptase was inactivated at $85^{\circ} \mathrm{C}$ for 5 mins. BER cDNA expression level was measured by reverse transcription-polymerase chain reaction (RT-PCR) via Prime Script RT-PCR Kit (Takara Biochemicals, Tokyo, Japan) following the manual suggestion. RT-PCR reaction was performed at ABI PRISM 7500FAST PCR Sequence Detection System (Thermo Fisher Scientific, Foster, USA) using the following parameters: $95^{\circ} \mathrm{C}$ for $10 \mathrm{mins}, 40$ cycles at $95^{\circ} \mathrm{C}$ for $10 \mathrm{~s}$, at $60^{\circ} \mathrm{C}$ for $20 \mathrm{~s}$ and at $72^{\circ} \mathrm{C}$ for $30 \mathrm{~s}$. The primers used are listed in Table 1. Relative gene expression level was calculated by comparing to reference GAPDH gene.

\section{Statistical analysis}

All data were obtained from triplicate independent experiments and were presented as mean \pm standard deviation. $P<0.05$ was considered to indicate a statistically significant difference. Statistical analysis was performed using SPSS version 18.0 (IBM, Armonk, USA) and GraphPad Prism version 6.0 (GraphPad Software Inc., San Diego, USA). One-way ANOVA and the Student-Newman Keuls tests (SNK) were used to compare means of each pair from different groups.
Table I Base excision repair (BER) family members related primer sequences (from $5^{\prime}$ to $3^{\prime}$ ) used in RT-qPCR

\begin{tabular}{|l|l|l|}
\hline Gene & Primer & Sequence \\
\hline GAPDH & $\begin{array}{l}\text { Forward } \\
\text { Reverse }\end{array}$ & $\begin{array}{l}\text { TGACTTCAACAGCGACACCCA } \\
\text { CACCCTGTTGCTGTAGCCAAA }\end{array}$ \\
\hline UNG & $\begin{array}{l}\text { Forward } \\
\text { Reverse }\end{array}$ & $\begin{array}{l}\text { GGTGTTCTCCTTCTCAACGCTGTC } \\
\text { ACATGGTGCCGCTTCCTATCAATG }\end{array}$ \\
\hline MMUGI & $\begin{array}{l}\text { Forward } \\
\text { Reverse }\end{array}$ & $\begin{array}{l}\text { TCTGTGGACAGCCTGAGGTCTTC } \\
\text { AGGCAGCTCAGCAGGAGTAAGG }\end{array}$ \\
\hline TDG & $\begin{array}{l}\text { Forward } \\
\text { Reverse }\end{array}$ & $\begin{array}{l}\text { GCAAGAACCGCAGACTGGAGAG } \\
\text { TGCACCTGCTTCCACTCATTGAC }\end{array}$ \\
\hline OGGI & $\begin{array}{l}\text { Forward } \\
\text { Geverse }\end{array}$ & $\begin{array}{l}\text { TGGACGGTGGTACAAGCCTGGAGGAG } \\
\text { TGGCTCTTGTCTCCTCGGTACGGTAAG }\end{array}$ \\
\hline MUTYH & $\begin{array}{l}\text { Forward } \\
\text { Reverse }\end{array}$ & $\begin{array}{l}\text { CGGAAGGTGGTAGAGGAGCTAGG } \\
\text { GCACCAATGGCTCGGACACG }\end{array}$ \\
\hline NEILI & $\begin{array}{l}\text { Forward } \\
\text { Reverse }\end{array}$ & $\begin{array}{l}\text { GCACACCTTCGCCTCCGATTC } \\
\text { GTTGCGGCTGACAGAGGACTTC }\end{array}$ \\
\hline
\end{tabular}

Abbreviations: UNG, uracil-DNA glycosylase; SMUGI, single-strand-selective monofunctional uracil-DNA glycosylase I; MBD4, Methyl-CpG binding domain 4; TDG, thymine DNA glycosylase; OGGI, 8-oxoguanine DNA glycosylase; MUTYH, MutY DNA glycosylase; NEILI, Nei like DNA glycosylase I.

\section{Results}

\section{Prognostic role of BER system in gastric cancer patients}

In the KM plotter database, all 7 BER genes (UNG, SMUG1, MBD4, TDG, OGG1, MUTYH and NEIL1) are related to OS of gastric cancer patients. The curves of OS were plotted from $876 \mathrm{GC}$ patients and separated to intestinal type $(n=320)$, diffuse type $(n=241)$, mixed type $(n=32)$ based on Lauren classification. We initially evaluated the prognostic value of UNG in the database, whose Affymetrix ID is 202330_s_at. As shown in Figure 1, the high expression of UNG mRNA was found to be correlated to high overall survival probability in all GC patients $(\mathrm{HR}=0.6(0.48-$ $0.74), P=2.8 \mathrm{e}-6)$. Furthermore, intestinal type $(\mathrm{HR}=0.53$ $(0.39-0.73), P=6.5 \mathrm{e}-5)$ and diffuse type $(\mathrm{HR}=0.61(0.43-$ $0.86), P=0.0039$ ) are related to high expression of UNG; the mixed type of GC showed less association.

High mRNA expression of SMUG1 (Affymetrix ID: 223684_s_at) was negatively correlated to OS in all GC patients (Figure 2, $\mathrm{HR}=1.78(1.46-2.18), P=1.4 \mathrm{e}-8)$. Both intestinal and diffuse-type $\mathrm{GC}$ results $(\mathrm{HR}=2(1.45-2.47)$, $P=1.3 \mathrm{e}-5, \mathrm{HR}=1.59$ (1.13-2.24), $P=0.00078$, respectively) 
UNG(202330_s_at)
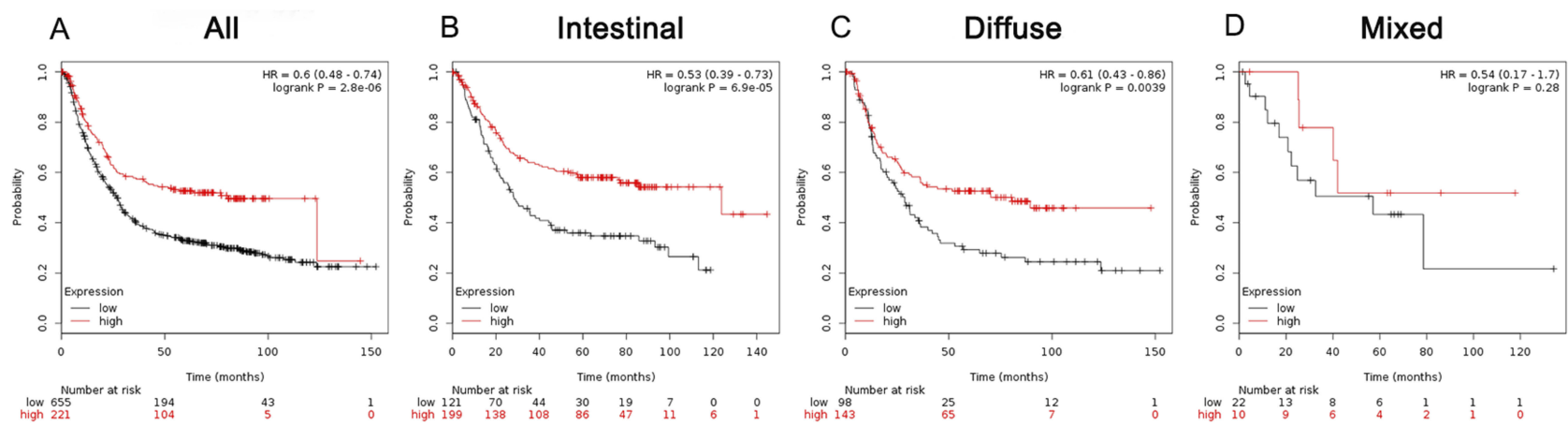

Figure I The prognostic significance of UNG expression in GC. The prognostic value of uracil-DNA glycosylase (UNG) expression in www.kmplot.com. Affymetrix ID for UNG: 202330_s_at. OS curves were plotted for $(\mathbf{A})$ all the patients $(n=882),(B)$ instestinal cancer patients $(n=336),(\mathbf{C})$ diffuse cancer patients $(n=248)$, and $(\mathbf{D})$ mixed cancer patients $(\mathrm{n}=33)$.
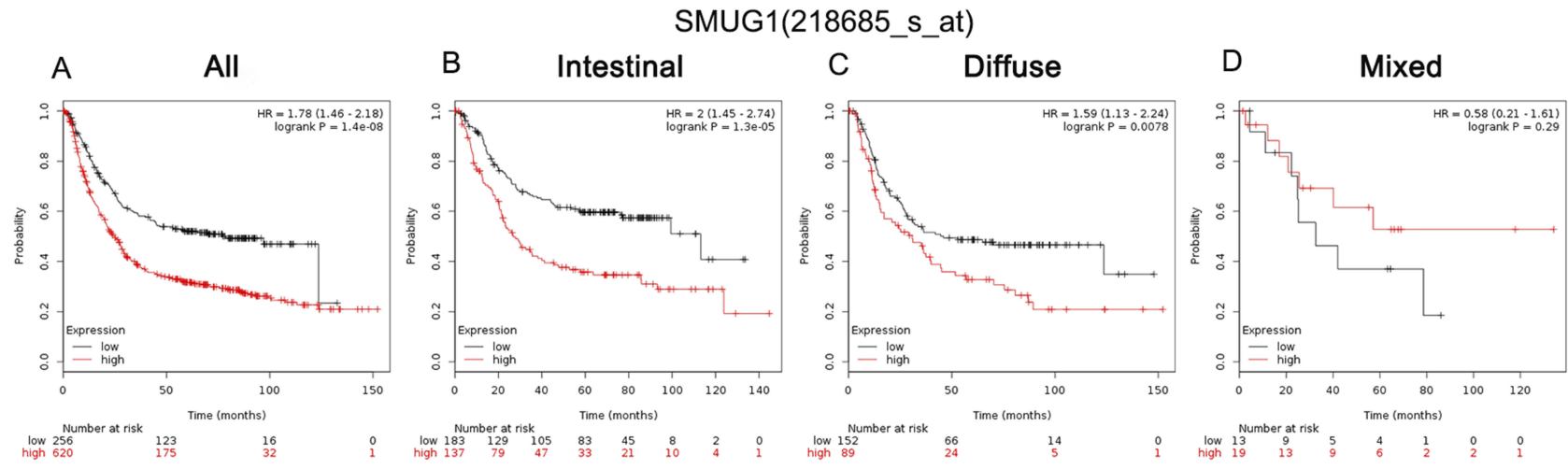

Figure 2 The prognostic significance of SMUGI expression in GC. The prognostic value of Single-strand-selective monofunctional uracil-DNA glycosylase I (SMUGI) expression in www.kmplot.com. Affymetrix ID for SMUGI: 223684_s_at. OS curves were plotted for (A) all the patients ( $n=882$ ), (B) instestinal cancer patients ( $n=336$ ), (C) diffuse cancer patients $(n=248)$, and (D) mixed cancer patients $(n=33)$.

further confirmed the results. As shown in Figure 3, high expression of MBD4 (Affymetrix ID: 209579_s_at) was associated with low overall survival probability in all GC patients (HR=1.49 (1.24-1.8), $P=2.8 \mathrm{e}-5)$ but had no effect on OS of three variety patients.
Figures 4 and 5 reveal the prognostic value of TDG (Affymetrix ID: 203742_s_at) and OGG1 (Affymetrix ID: 205760_s_at) mRNA expression in the database. Elevated mRNA expression of both TDG and OGG1 were associated with an unfavorable OS in all the GC patients, the intestinal

\section{MBD4(209579_s_at)}
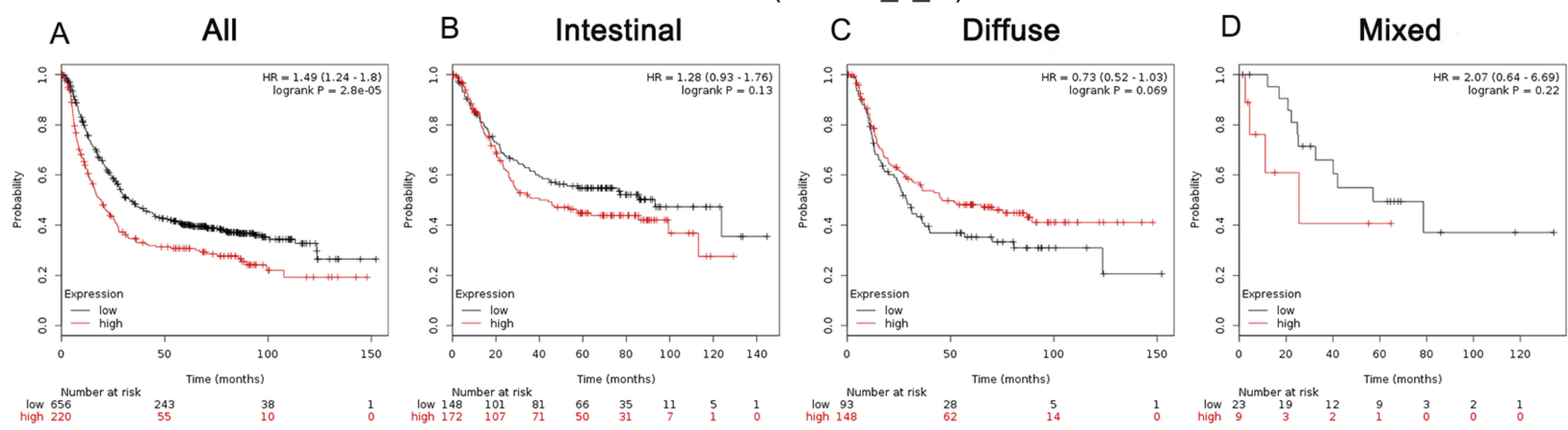

Figure 3 The prognostic significance of MBD4 expression in GC. The prognostic value of Methyl-CpG binding domain 4 (MBD4) expression in www.kmplot.com. Affymetrix ID for MBD4: 209579_s_at. OS curves were plotted for $(\mathbf{A})$ all the patients $(n=882)$, $(\mathbf{B})$ instestinal cancer patients $(n=336)$, $(\mathbf{C})$ diffuse cancer patients ( $n=248)$, and (D) mixed cancer patients $(n=33)$. 

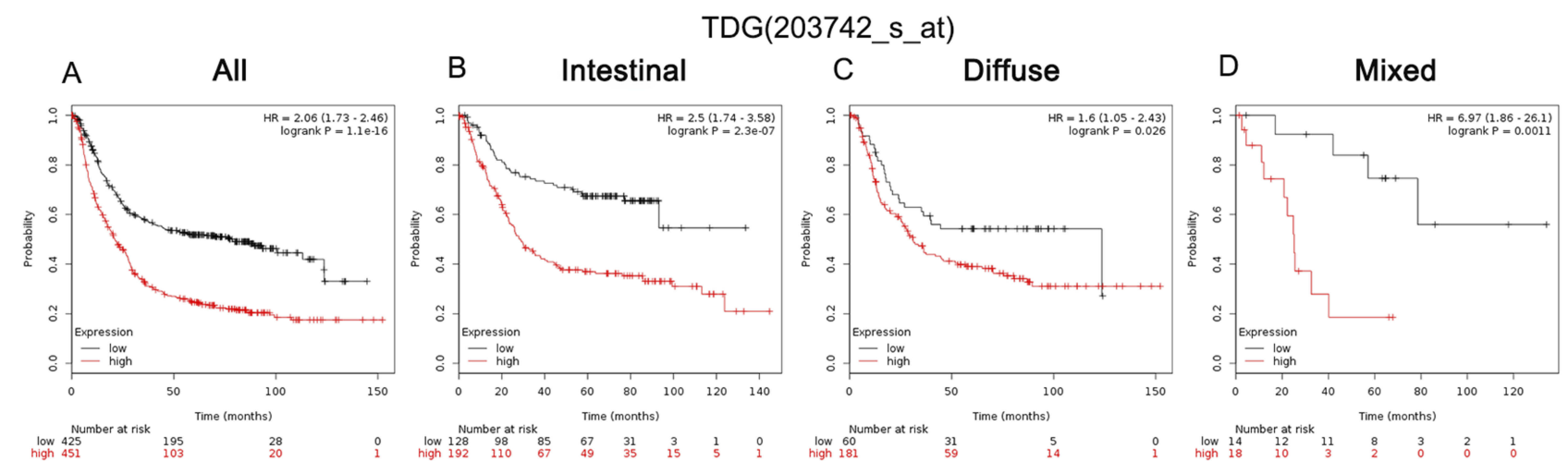

Figure 4 The prognostic significance of TDG expression in GC. The prognostic value of Thymine DNA glycosylase (TDG) expression in www.kmplot.com. Affymetrix ID for TDG: 203742_s_at. OS curves were plotted for (A) all the patients $(n=882),(B)$ instestinal cancer patients $(n=336),(\mathbf{C})$ diffuse cancer patients $(n=248)$, and (D) mixed cancer patients $(n=33)$.
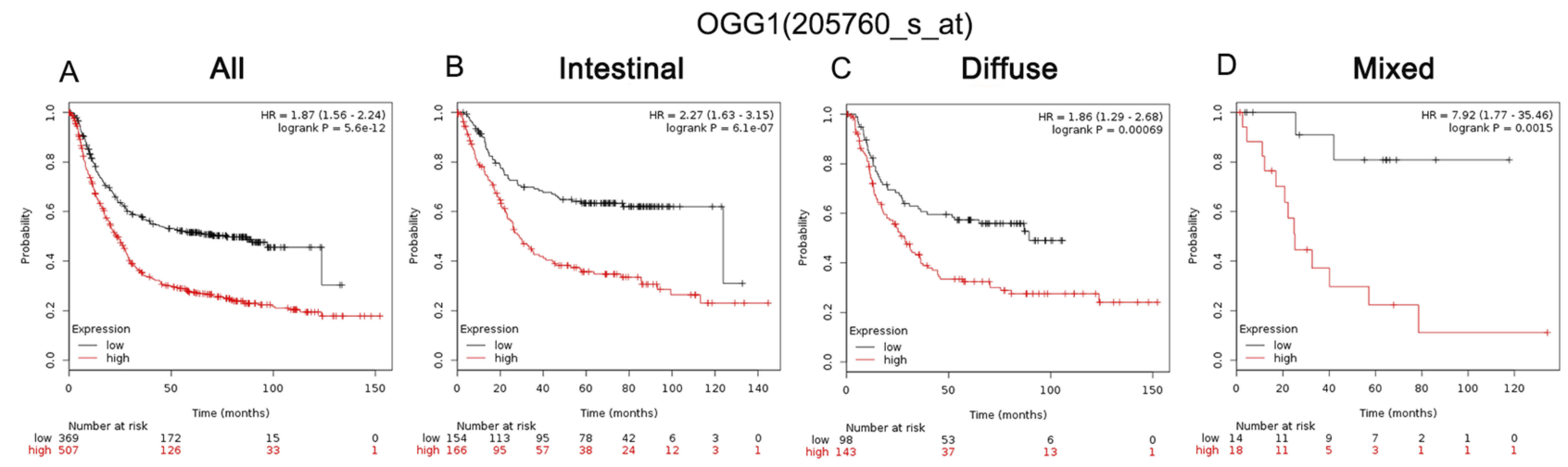

Figure 5 The prognostic significance of OGGI expression in GC. The prognostic value of 8-oxoguanine DNA glycosylase (OGGI) expression in www.kmplot.com. Affymetrix ID for OGGI: 205760_s_at. OS curves were plotted for $(\mathbf{A})$ all the patients $(n=882),(B)$ instestinal cancer patients $(n=336)$, $(\mathbf{C})$ diffuse cancer patients ( $n=248)$, and (D) mixed cancer patients $(n=33)$.

type patients, the diffuse type patients and the mixed type patients. In TDG, the KM plotter results are as follows: all GC patients $(\mathrm{HR}=2.06(1.73-2.46), P=1.1 \mathrm{e}-16)$, intestinal type $(\mathrm{HR}=2.5(1.74-3.58), P=2.3 \mathrm{e}-7)$, diffuse type $(\mathrm{HR}=1.6$ (1.05-2.43), $P=0.026)$, mixed type (HR=6.97 (1.86-26.1), $P=0.0011)$. In OGG1, the KM plotter results are as follows: all $\mathrm{GC}$ patients $(\mathrm{HR}=1.87(1.56-2.24), P=5.6 \mathrm{e}-12)$, intestinal type $(\mathrm{HR}=2.27(1.63-3.15), P=6.1 \mathrm{e}-7)$, diffuse type $(\mathrm{HR}=1.86 \quad(1.29-2.68), \quad P=0.00069)$ and mixed type (HR=7.92 (1.77-35.46), $P=0.0015)$.

We then determined the correlation between prognostic effect and the expression of MUTYH (Affymetrix IDs: 207727_s_at) in KM plotter (Figure 6). High mRNA expression of MUTYH was significantly correlated to low overall survival probability in all GC patients $(\mathrm{HR}=1.4 \quad(1.22-1.72), \quad P=1.5 \mathrm{e}-5)$ and intestinal-type patients $(\mathrm{HR}=1.93(1.41-2.65), P=3.2 \mathrm{e}-5)$. However, the curves of MUTYH expression above or below the median do not separate the cases into significantly different prognostic groups in either diffuse or mixed type ( $P=0.071$ in diffuse and 0.063 in mixed, respectively).

Figure 7 illustrates the prognostic value of NEIL1 (Affymetrix IDs: 219396_s_at) in the database. The high mRNA expression level of NEIL1 mRNA was significantly associated with low overall survival probability in all GC cancer patients $(\mathrm{HR}=1.88(1.55-2.29), P=6.9 \mathrm{e}-11)$. In accordance with the result, both intestinal and diffuse-type led to low overall survival probability (Intestinal type: $\mathrm{HR}=2.28$ (1.56-3.34), $P=1.3 \mathrm{e}-5$, diffuse type: $\mathrm{HR}=1.45(1.03-2.05)$, $P=0.034)$. Additionally, there was no significant difference between NEIL1 mRNA expression and OR of mixed type.

To further explore the association between individual BER system genes and other clinicopathological profiles, we analyzed the correlation of OS with pathological stages (Table 2), HER2 expression status (Table 3), treatment strategy (Table 4), gender (Table 5) and different gastric cancer degree (Table 6). As shown in Table 2, high expression of UNG gene showed a better correlation to OS in stage 1,2 and 

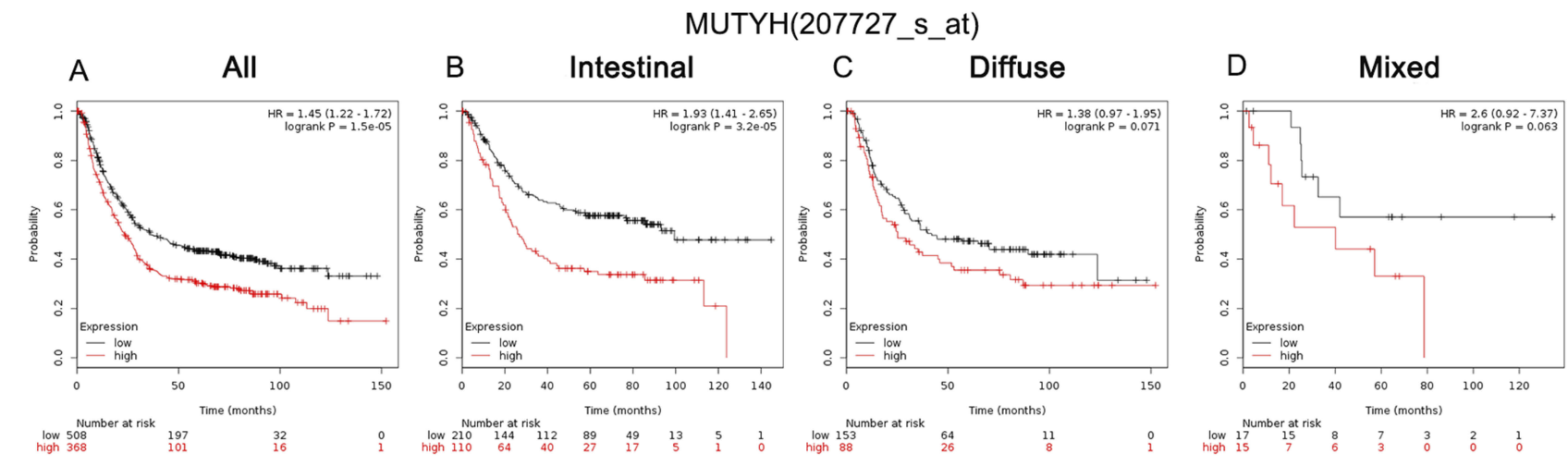

Figure 6 The prognostic significance of MUTYH expression in GC. The prognostic value of MutY DNA glycosylase (MUTYH) expression in www.kmplot.com. Affymetrix ID for MUTYH: 207727_s_at. OS curves were plotted for $(\mathbf{A})$ all the patients $(n=882),(B)$ instestinal cancer patients $(n=336),(\mathbf{C})$ diffuse cancer patients $(n=248)$, and $(\mathbf{D})$ mixed cancer patients $(n=33)$.
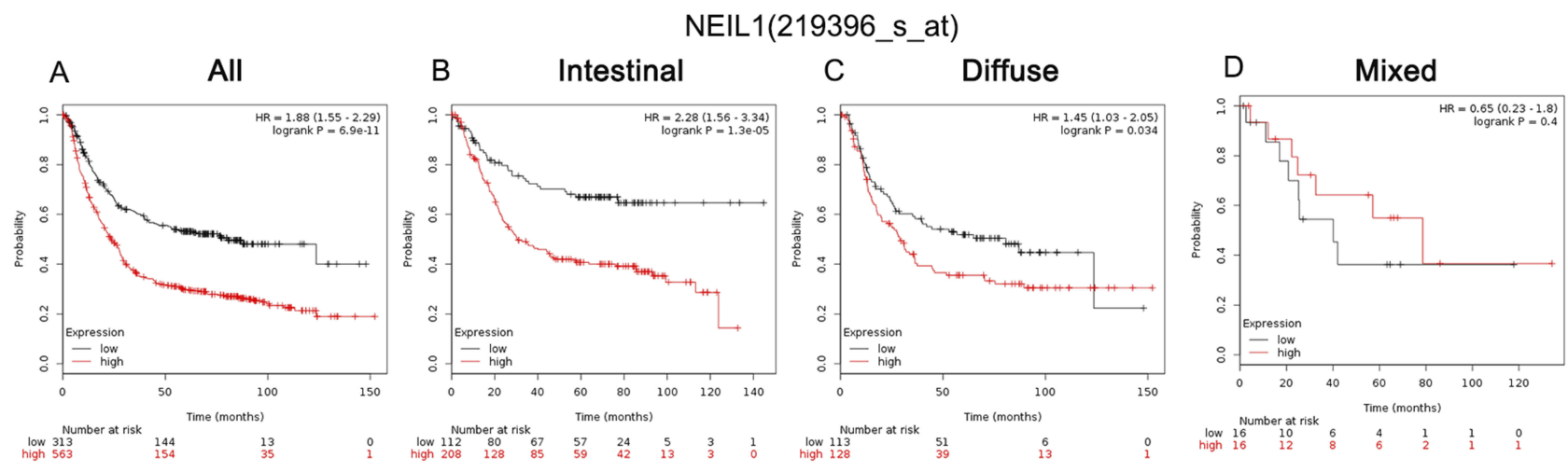

Figure 7 The prognostic significance of NEILI expression in GC. The prognostic value of Nei like DNA glycosylase I (NEILI) expression in www.kmplot.com. Affymetrix ID for NEILI: 219396_s_at. OS curves were plotted for $(\mathbf{A})$ all the patients $(n=882),(\mathbf{B})$ instestinal cancer patients $(n=336),(\mathbf{C})$ diffuse cancer patients $(n=248)$, and $(\mathbf{D})$ mixed cancer patients $(n=33)$.

$3 \mathrm{GC}$ patients, and high expressed MUTYH is related to OS of stage $4 \mathrm{GC}$ patients. OGG1 was $\mathrm{r}$ associated with an unfavorable OS in all 4 stages of GC. SMUG1, TDG, MUTYH and NEIL1 linked with negative OS in most GC stages (Table 2). UNG, SMUG1, MBD4, TDG, OGG1 and NEIL1 were all associated with worse OS either in negative or positive HER2 expression group (Table 3). UNG and SMUG1 were significantly associated with better OS in different GC treatment strategy including surgery alone and 5-FU based adjuvant (Table 4). In Table 5, only high expression of UNG correlated to an improved OS in female and male GC patients. Contrastively, SMUG1, TDG, OGG1, MUTYH and NEIL1 were all associated with worse OS both in female and male group. Unexpectedly, high UNG mRNA expressions were associated with worse OS in poor differentiation based on differentiation degree of GC patients as shown in Table 6. Moreover, SMUG1 and TDG mRNA expression were associated with poor OS in good differentiation degree of GC patient.

\section{Blocking DNA damage repair suppresses gastric cancer proliferation and induces}

\section{apoptosis}

To further understand the function of seven BER family members, we utilized WEB-based Gene SeT AnaLysis Toolkit (WebGestalt, http://www.webgestalt.org) to analysis the enriched signaling pathway. BER family members participate in almost all DNA damage repair process (Table 7). To explore the regulation mechanism of BER in gastric cancer, we selected a widely used DNA damage repair inhibitorBerzosertib (VE-822) to treat two commonly used gastric cell lines. ${ }^{7,8}$ Compared to DMSO solvent control group, Label-free Real-time Cellular Analysis (RTCA) showed that the ability of BGC-832 (Figure 8A) and MKN-45 (Figure 8B) cells proliferation was obviously inhibited depending on VE822 concentration.

To investigate the effects of VE-822 on the apoptosis of gastric cancer cell lines, we treated BGC-832 and MKN-45 cells with VE- 822 with $2 \mu \mathrm{M}, 4 \mu \mathrm{M}, 6 \mu \mathrm{M}, 8 \mu \mathrm{M}, 10 \mu \mathrm{M}$ for 
Table 2 Correlation of base excision repair (BER) system genes expression level with overall survival (OS) in gastric cancer patients with different pathological stages

\begin{tabular}{|c|c|c|c|c|}
\hline BER system & Stages & Cases & HR $(95 \% \mathrm{Cl})$ & $P$-value \\
\hline \multirow[t]{4}{*}{ UNG } & I & 67 & $0.24(0.08-0.75)$ & $0.0084^{*}$ \\
\hline & 2 & 140 & $0.55(0.3-1)$ & $0.048^{*}$ \\
\hline & 3 & 305 & $0.6(0.45-0.8 I)$ & $0.00078 *$ \\
\hline & 4 & 148 & $0.79(0.5 I-1.24)$ & 0.3 \\
\hline \multirow[t]{4}{*}{ SMUGI } & I & 67 & $2.01(0.56-7.14)$ & 0.27 \\
\hline & 2 & 140 & 2.45 (1.34-4.48) & $0.0026 *$ \\
\hline & 3 & 305 & $1.86(1.4-2.48)$ & $1.6 \mathrm{e}-05^{*}$ \\
\hline & 4 & 148 & $0.76(0.49-1.2)$ & 0.24 \\
\hline \multirow[t]{4}{*}{ MBD4 } & I & 67 & $2.33(0.84-6.42)$ & 0.093 \\
\hline & 2 & 140 & $1.35(0.72-2.52)$ & 0.35 \\
\hline & 3 & 305 & $0.78(0.57-1.08)$ & 0.14 \\
\hline & 4 & 148 & I.5 (0.97-2.3) & 0.066 \\
\hline \multirow[t]{4}{*}{ TDG } & I & 67 & $3.03(1.12-8.17)$ & $0.021 *$ \\
\hline & 2 & 140 & $1.75(0.96-3.2)$ & 0.066 \\
\hline & 3 & 305 & $2.02(1.4 I-2.9)$ & $9.3 e-05^{*}$ \\
\hline & 4 & 148 & $1.58(1.07-2.33)$ & $0.02 I^{*}$ \\
\hline \multirow[t]{4}{*}{ OGGI } & I & 67 & $10.64(1.39-81.4)$ & $0.0047^{*}$ \\
\hline & 2 & 140 & $2.08(1.14-3.78)$ & $0.015^{*}$ \\
\hline & 3 & 305 & $2.13(1.54-2.94)$ & $3.3 e-06 *$ \\
\hline & 4 & 148 & $1.66(1.09-2.54)$ & $0.018^{*}$ \\
\hline \multirow[t]{4}{*}{ MUTYH } & 1 & 67 & $6.26(1.42-27.59)$ & $0.0055^{*}$ \\
\hline & 2 & 140 & $1.36(0.75-2.47)$ & 0.31 \\
\hline & 3 & 305 & $1.84(1.28-2.64)$ & $0.00074 *$ \\
\hline & 4 & 148 & $0.64(0.4 I-0.98)$ & $0.039 *$ \\
\hline \multirow[t]{4}{*}{ NEILI } & I & 67 & $4.17(1.5-11.57)$ & $0.003^{*}$ \\
\hline & 2 & 140 & $2.7(1.45-5.04)$ & $0.0012^{*}$ \\
\hline & 3 & 305 & $1.7(1.27-2.27)$ & $0.00028 *$ \\
\hline & 4 & 148 & $0.69(0.44-1.08)$ & 0.1 \\
\hline
\end{tabular}

Note: $* P<0.05$.

Abbreviations: $\mathrm{Cl}$, confidence interval; $\mathrm{HR}$, hazard ratio; UNG, uracil-DNA glycosylase; SMUGI, single-strand-selective monofunctional uracil-DNA glycosylase I; MBD4, Methyl-CpG binding domain 4; TDG, thymine DNA glycosylase; OGGI, 8-oxoguanine DNA glycosylase; MUTYH, MutY DNA glycosylase; NEILI, Nei like DNA glycosylase I.

$48 \mathrm{hrs}$. And apoptosis was evaluated using the annexin V/PI assay. Apoptosis assay showed that VE-822 treatment exhibited an obvious increase in the percent of apoptotic cells compared to the control group. VE-822 induced apoptosis increasing from $2.25 \%$ to $4.07 \%$ in BGC-832 cells and $6.63 \%$ to $12.99 \%$ in $\mathrm{MKN}-45$ cells, respectively, depending on VE-822 concentration (Figure 9).

\section{VE-822 inhibits proliferation and migration of gastric cancer cells}

To examine the effect of VE-822 on gastric cancer cell proliferation, we conducted a colony formation assay.
Table 3 Correlation of base excision repair (BER) system genes expression with overall survival (OS) in gastric cancer patients with HER2 expression status

\begin{tabular}{|c|c|c|c|c|}
\hline $\begin{array}{l}\text { BER } \\
\text { system }\end{array}$ & $\begin{array}{l}\text { HER } 2 \\
\text { status }\end{array}$ & Cases & HR (95\% Cl) & $P$-value \\
\hline \multirow[t]{2}{*}{ UNG } & Negative & 298 & $1.42(1.08-1.88)$ & $0.013^{*}$ \\
\hline & Positive & 295 & $1.48(1.13-1.94)$ & $0.0044 *$ \\
\hline \multirow[t]{2}{*}{ SMUGI } & Negative & 532 & $1.64(1.3-2.09)$ & $3.6 \mathrm{e}-05^{*}$ \\
\hline & Positive & 344 & $1.47(1.12-1.93)$ & $0.0054^{*}$ \\
\hline \multirow[t]{2}{*}{ MBD4 } & Negative & 532 & $1.29(1.01-1.66)$ & $0.041 *$ \\
\hline & Positive & 344 & $1.75(1.31-2.35)$ & $0.00014^{*}$ \\
\hline \multirow[t]{2}{*}{ TDG } & Negative & 532 & $2.05(1.64-2.57)$ & $2.1 \mathrm{e}-10^{*}$ \\
\hline & Positive & 344 & $2.44(1.87-3.18)$ & $9.9 \mathrm{e}-12^{*}$ \\
\hline \multirow[t]{2}{*}{ OGGI } & Negative & 532 & $2.05(1.6-2.63)$ & $7.2 \mathrm{e}-09^{*}$ \\
\hline & Positive & 344 & $1.68(1.25-2.27)$ & $0.00052 *$ \\
\hline \multirow[t]{2}{*}{ MUTYH } & Negative & 532 & $1.46(1.16-1.85)$ & $0.0014^{*}$ \\
\hline & Positive & 344 & $1.29(0.99-1.67)$ & 0.057 \\
\hline \multirow[t]{2}{*}{ NEILI } & Negative & 532 & $2.02(1.57-2.59)$ & $2.5 \mathrm{e}-08^{*}$ \\
\hline & Positive & 344 & $1.62(1.23-2.14)$ & $0.00055^{*}$ \\
\hline
\end{tabular}

Note: $* P<0.05$.

Abbreviations: $\mathrm{Cl}$, confidence interval; $\mathrm{HR}$, hazard ratio; HER2, human epidermal growth factor receptor-2; UNG, uracil-DNA glycosylase; SMUGI, single-strandselective monofunctional uracil-DNA glycosylase I; MBD4, Methyl-CpG binding domain 4; TDG, thymine DNA glycosylase; OGGI, 8-oxoguanine DNA glycosylase; MUTYH, MutY DNA glycosylase; NEILI, Nei like DNA glycosylase I.

Colony formation assay revealed that VE-822 caused a significant inhibition in the proliferative capability of the BGC-832 and MKN-45 cells in a concentration-dependent manner (Figure 10). Scratch test was performed in vitro to investigate the ability of migration under VE-822 condition. Scratch test revealed that VE-822 significantly inhibited cell migration capacity of BGC-832 (Figure 11).

\section{VE-822 suppresses gastric cells proliferation by influencing BER genes expression}

To confirm the previous BER genes expression and OS relationship from $\mathrm{KM}$ plotter database, we tested the expression of BER genes in two gastric cancer cell lines compared to normal gastric cell GES-1 that is commonly used human gastric epithelium. ${ }^{9}$ Consisted with KM plotter analysis, BER members including SMUG, MBD4, MUTYH, NEIL1 and OGG1 with poor prognosis were highly expressed in gastric cancer cells (BGC-832 and MKN-45) and BER members including UNG and TDG with good prognosis were highly expressed in normal gastric cells (GES-1) (Figure 12A). 
Table 4 Correlation of base excision repair (BER) system genes expression with overall survival (OS) in gastric cancer patients with different treatment strategies

\begin{tabular}{|c|c|c|c|c|}
\hline BER & Treatment & Cases & HR (95\% Cl) & $P$-value \\
\hline \multirow[t]{3}{*}{ UNG } & Surgery alone & 380 & $0.6(0.42-0.87)$ & $0.0069 *$ \\
\hline & 5 FU-based adjuvant & 153 & $2.55(1.76-3.68)$ & $3 e-07^{*}$ \\
\hline & Other adjuvant & 80 & Not available & Not available \\
\hline \multirow[t]{3}{*}{ SMUGI } & Surgery alone & 380 & $1.41(1.05-1.89)$ & $0.022^{*}$ \\
\hline & 5 FU-based adjuvant & 153 & $1.58(1.09-2.3)$ & $0.015^{*}$ \\
\hline & Other adjuvant & 76 & $0.29(0.1-0.86)$ & $0.017^{*}$ \\
\hline \multirow[t]{3}{*}{ MBD4 } & Surgery alone & 380 & $1.6(1.17-2.18)$ & $0.003^{*}$ \\
\hline & 5 FU-based adjuvant & 153 & $1.3(0.89-1.89)$ & 0.18 \\
\hline & Other adjuvant & 76 & $0.5(0.2|-| .2 I)$ & 0.12 \\
\hline \multirow[t]{3}{*}{ TDG } & Surgery alone & 380 & $1.72(1.27-2.32)$ & $0.00036^{*}$ \\
\hline & 5 FU-based adjuvant & 153 & $2.13(1.48-3.06)$ & $3 e-05^{*}$ \\
\hline & Other adjuvant & 76 & I.8I (0.72-4.53) & 0.2 \\
\hline \multirow[t]{3}{*}{ OGGI } & Surgery alone & 380 & $1.88(1.4-2.52)$ & $1.7 e-05^{*}$ \\
\hline & 5 FU-based adjuvant & 153 & $0.77(0.52-1.15)$ & 0.2 \\
\hline & Other adjuvant & 76 & $2.09(0.85-5.13)$ & 0.098 \\
\hline \multirow[t]{3}{*}{ MUTYH } & Surgery alone & 380 & $0.87(0.65-1.17)$ & 0.37 \\
\hline & 5 FU-based adjuvant & 153 & $1.75(1.23-2.48)$ & $0.0017^{*}$ \\
\hline & Other adjuvant & 76 & $3.26(0.75-14.07)$ & 0.094 \\
\hline \multirow[t]{3}{*}{ NEILI } & Surgery alone & 380 & $1.48(1.11-1.98)$ & $0.0079 *$ \\
\hline & 5 FU-based adjuvant & 153 & $1.26(0.88-1.82)$ & 0.21 \\
\hline & Other adjuvant & 76 & $2.4(0.87-6.6 I)$ & 0.08 \\
\hline
\end{tabular}

Note: $* P<0.05$.

Abbreviations: 5-FU, 5-Fluorouracil; Cl, confidence interval; HR, hazard ratio; UNG, uracil-DNA glycosylase; SMUGI, single-strand-selective monofunctional uracil-DNA glycosylase I; MBD4, Methyl-CPG binding domain 4; TDG, thymine DNA glycosylase; OGGI, 8-oxoguanine DNA glycosylase; MUTYH, MutY DNA glycosylase; NEILI, Nei like DNA glycosylase I.

Based on the RT-PCR confirmation, we further wanted to explore the suppression of gastric cancer cells by VE822 involving in BER system or not. After 48 hrs of VE822 treatment, we observed that mRNA expression levels of UNG (Figure 12B) were significantly increased in the gastric cancer cells (BGC-832 and MKN-45), and the levels of MUTYH (Figure 12C) and OGG1 (Figure 12D) were significantly decreased in the gastric cancer cells (BGC-832 and MKN-45). The mRNA expression levels of other BER family members exhibited no difference between normal and two gastric cancer cell lines.

\section{Discussion}

The previous study suggests that UNG is responsible for modification of one most common uracil base UNG collaborated with SMUG1 effectively to restrict deoxyuridine (dU) accumulation in DNA by recruiting critical DNA repair factors. ${ }^{10}$ In the regulation, mechanism of UNG in B cells was clear. Activation-induced cytidine deaminase required class switch recombination and somatic hypermutation; during the process, UNG promotes the former one and suppresses the latter one. ${ }^{11-13}$ Moreover, there was also a negative correlation between UNG expression and APOBEC3B (apolipoprotein B mRNA-editing enzyme, catalytic polypeptide-like 3) in mature B-cell lymphoma cells. ${ }^{13}$ An important carcinogenic factor is a viral infection which may be caused by up-regulation of APOBEC3B. ${ }^{13}$ APOBEC3B gene up-regulation increased cancer risk with $5-10 \%$ up-regulated in lower end spectrum tumors and nearly $90-95 \%$ up-regulated in higher end spectrum tumors. ${ }^{14-16}$ UNG plays a reverse role against $\mathrm{APOBEC} 3 \mathrm{~B}$ by affecting its mutagenesis. ${ }^{13}$ In accordance with previous studies, our KM plotter results also showed only high UNG expression was associated with high overall survival probability in gastric cancer patients that suggested UNG may take a major role in BER-related DNA damage repair. In gastric cancer, APOBEC3B has been improved to highly express in 
Table 5 Correlation of base excision repair (BER) system genes expression with overall survival (OS) in gastric cancer patients with gender expression status

\begin{tabular}{|c|c|c|c|c|}
\hline BER & Gender & Cases & HR (95\% Cl) & $P$-value \\
\hline \multirow[t]{2}{*}{ UNG } & Female & 236 & $0.45(0.3-0.67)$ & $7.5 e-05^{*}$ \\
\hline & Male & 548 & $0.64(0.49-0.83)$ & $0.00073^{*}$ \\
\hline \multirow[t]{2}{*}{ SMUGI } & Female & 236 & $1.85(1.28-2.66)$ & $0.00078^{*}$ \\
\hline & Male & 545 & I.8 (I.42-2.29) & $8.7 \mathrm{e}-07^{*}$ \\
\hline \multirow[t]{2}{*}{ MBD4 } & Female & 236 & $1.4(0.96-2.03)$ & 0.076 \\
\hline & Male & 545 & $1.61(1.28-2.03)$ & $5.2 e-05^{*}$ \\
\hline \multirow[t]{2}{*}{ TDG } & Female & 236 & $2.17(1.5 I-3.1)$ & $1.5 \mathrm{e}-05^{*}$ \\
\hline & Male & 545 & $2.26(\mathrm{I} .8 \mathrm{I}-2.8 \mathrm{I})$ & $7.2 \mathrm{e}-14^{*}$ \\
\hline \multirow[t]{2}{*}{ OGGI } & Female & 236 & $1.67(1.16-2.39)$ & $0.005^{*}$ \\
\hline & Male & 545 & $2.17(I .73-2.7 I)$ & $6.5 \mathrm{e}-12^{*}$ \\
\hline \multirow[t]{2}{*}{ MUTYH } & Female & 236 & $1.78(1.25-2.54)$ & $0.0012^{*}$ \\
\hline & Male & 545 & $1.56(1.26-1.94)$ & $4 e-05^{*}$ \\
\hline \multirow[t]{2}{*}{ NEILI } & Female & 236 & $2.15(1.43-3.25)$ & $0.00017^{*}$ \\
\hline & Male & 545 & $1.95(1.53-2.47)$ & $2.4 \mathrm{e}-08^{*}$ \\
\hline
\end{tabular}

Note: $* P<0.05$.

Abbreviations: $\mathrm{Cl}$, confidence interval; $\mathrm{HR}$, hazard ratio; UNG, uracil-DNA glycosylase; SMUGI, single-strand-selective monofunctional uracil-DNA glycosylase I; MBD4, Methyl-CPG binding domain 4; TDG, thymine DNA glycosylase; OGGI, 8oxoguanine DNA glycosylase; MUTYH, MutY DNA glycosylase; NEILI, Nei like DNA glycosylase I.

gastric cancer tissues. ${ }^{17}$ Combined with our UNG KM plotter analysis, one possible mechanism of UNG in improving overall survival of gastric cancer may be by affecting APOBEC3B.

For SMUG1, high mRNA expression was negatively correlated to OS in all GC patients, correspondingly to the consequence of both intestinal and diffuse-type GC. As a back-up role in somatic hypermutation, its function is also controlling accurate repairment of uracils after binding to AP-sites stably in DNA and inhibiting the downstream activity of APE1 (AP-endonuclease). It also excises oxidized 5-formyluracil, 5-hydroxymethyluracil and 5-hydroxyuracil. However, not only it cannot complement UNG in the repair of U:G mismatches, but persisting mutations at A-T base pairs only in $\mathrm{UNG}^{-/-}$mice were generated by the expression of uracil glycosylases, SMUG1 and TDG, in germinal center $\mathrm{B}$ cells and naive $\mathrm{B}$ cells. ${ }^{18}$ Besides, Dingler et al. suggested that SMUG1 stimulated B cells' mutagenesis, and during the immune response, the cells showed increased affinity and varied antibody function. ${ }^{19}$ Furthermore, compared with UNG, SMUG1 could resume the replication after 5-FU cancer chemotherapy, which leads to the RNA and DNA incorporation of FUTP and
Table 6 Correlation of base excision repair (BER) system genes expression with overall survival (OS) in gastric cancer patients with differentiation degree

\begin{tabular}{|l|l|l|l|l|}
\hline BER & Differentiated & Cases & HR (95\% CI) & P-value \\
\hline UNG & Poor & 165 & $1.61(1.07-2.44)$ & $0.022^{*}$ \\
& Moderate & 67 & $0.74(0.38-1.46)$ & 0.39 \\
& Good & 32 & $1.9(0.8-4.55)$ & 0.14 \\
\hline SMUGI & Poor & 165 & $1.3(0.87-1.93)$ & 0.2 \\
& Moderate & 67 & $0.57(0.28-1.15)$ & 0.11 \\
& Good & 32 & $3.72(1.34-10.27)$ & $0.0069 *$ \\
\hline \multirow{2}{*}{ MBD4 } & Poor & 165 & $0.69(0.46-1.03)$ & 0.068 \\
& Moderate & 67 & $1.66(0.8 I-3.41)$ & 0.16 \\
& Good & 32 & $0.52(0.18-1.56)$ & 0.24 \\
\hline TDG & Poor & 165 & $1.33(0.84-2.1)$ & 0.23 \\
& Moderate & 67 & $1.6(0.83-3.11)$ & 0.16 \\
& Good & 32 & $3.44(1.38-8.58)$ & $0.005 I^{*}$ \\
\hline \multirow{2}{*}{ OGGI } & Poor & 165 & $1.5(0.95-2.36)$ & 0.079 \\
& Moderate & 67 & $0.7(0.33-1.5)$ & 0.35 \\
& Good & 32 & $1.81(0.61-5.41)$ & 0.28 \\
\hline \multirow{2}{*}{ MUTYH } & Poor & 165 & $1.34(0.9-2.02)$ & 0.15 \\
& Moderate & 67 & $1.47(0.77-2.81)$ & 0.24 \\
& Good & 32 & $0.69(0.29-1.68)$ & 0.42 \\
\hline \multirow{2}{*}{ NEILI } & Poor & 165 & $0.83(0.55-1.26)$ & 0.39 \\
& Moderate & 67 & $0.58(0.3-1.13)$ & 0.11 \\
& Good & 32 & $3.11(0.91-10.61)$ & 0.056 \\
\hline
\end{tabular}

Note: $* P<0.05$.

Abbreviations: $\mathrm{Cl}$, confidence interval; $\mathrm{HR}$, hazard ratio; UNG, uracil-DNA glycosylase; SMUGI, single-strand-selective monofunctional uracil-DNA glycosylase I; MBD4, Methyl-CpG binding domain 4; TDG, thymine DNA glycosylase; OGGI, 8oxoguanine DNA glycosylase; MUTYH, MutY DNA glycosylase; NEILI, Nei like DNA glycosylase I.

FdUTP. $^{20}$ Thus, the association with neoplasm needs further study.

MBD4 is a major factor in response to oxidative stress, as an enzyme that controls base excision repair, DNA demethylation and gene expression regulation. It also functions as a mismatch-specific $\mathrm{N}$-glycosylase effective on uracil, thymine, 5-fluorouracil and 3,N(4)-ethenocytosine paired with guanine. ${ }^{21}$ Similar to our results, Chen's study showed that in $46 \%$ of non-muscle invasive tumors, MBD4 mRNA expression was reduced, while $11 \%$ was found in muscle-invasive tumors, indicating that high expression tended to be associated with higher tumor stage. At the same time, low level of MBD4 mRNA may be a favorable prognostic biomarker, which corresponds with our results. ${ }^{22}$ In sporadic GC, MBD4 frameshift mutations were found in $29 \%$, as high-frequently as in colon cancers, resulting in tumor progression. ${ }^{23}$ As for breast cancer, RON/MSP 
Table 7 Reactome enrichment analysis

\begin{tabular}{|l|l|l|l|}
\hline Gene set & Description & $\begin{array}{l}\text { P-value } \\
\text { False discovery } \\
\text { rate (FDR) }\end{array}$ \\
\hline R-HSA-73884 & Base Excision Repair & 0 & 0 \\
R-HSA-73929 & Resolution of Abasic Sites (AP sites) & 0 & 0 \\
R-HSA-I I0357 & Displacement of DNA glycosylase by APEXI & 0 & 0 \\
R-HSA-I I0328 & Recognition and association of DNA glycosylase with site containing an affected pyrimidine & 0 & 0 \\
R-HSA-I I0329 & Cleavage of the damaged pyrimidine & 0 & 0 \\
R-HSA-73928 & Depyrimidination & 0 & 0 \\
R-HSA-73894 & DNA Repair & $2.02 E-I I$ & $4.37 E-09$ \\
R-HSA-5649702 & APEXI-Independent Resolution of AP Sites via the Single Nucleotide Replacement Pathway & 7.9 IE-06 & 0.00 I5I8 \\
\hline
\end{tabular}

A

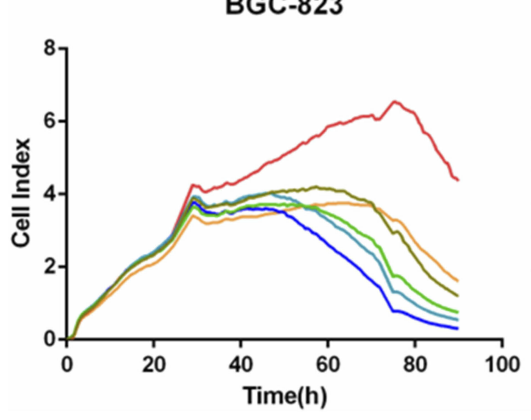

B

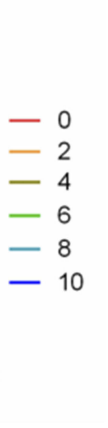

MKN-45

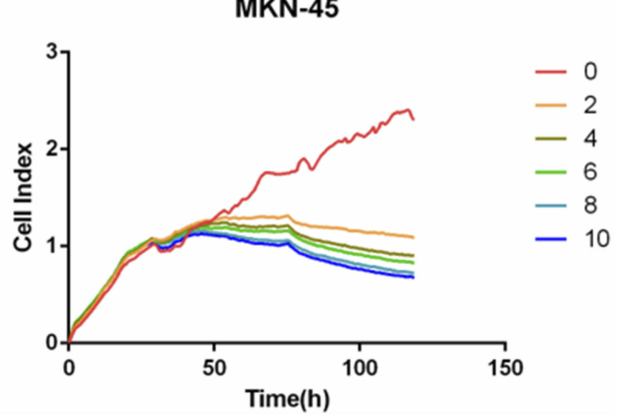

Figure 8 VE-822 inhibits proliferation of gastric cancer. Proliferation BGC-823 (A) and MKN-45 (B) cells of gastric cancer exposed to $0,2 \mu M, 4 \mu M, 6 \mu M, 8 \mu M, 10 \mu M$ VE822 detected by Label-free Real-time Cellular Analysis (RTCA).

(recepteur d'origine nantais/macrophage stimulating protein) can signal PI3K (phosphatidylinositol 3-kinase) to upregulate MBD4. And specific breast tumors show the RON/MBD4 epigenetic signature, which is associated with unfavorable prognosis. ${ }^{24}$ Moreover, in cervical cancer, MBD4 codon Glu346Lys polymorphism might bring about susceptibility in the Chinese population. ${ }^{25}$ Whether those conclusion can be applied to gastric cancer or not needs further exploration.

In our study, both elevated TDG and OGG1 mRNA expression were associated with an unfavorable OS in all the GC patients, the intestinal-type patients, the diffuse-type patients and the mixed-type patients. For another uracil-DNA N-glycosylase, TDG (Thymine DNA Glycosylase) can act as thymine on $\mathrm{G}$ : $\mathrm{T}$ and $\mathrm{G}$ : $\mathrm{U}$ mismatches to protect $\mathrm{CpG}$ sites in the genome from deamination-induced mutagenesis. In addition, TDG is able to remove the novel cytosine derivatives, 5formylcytosine and 5-carboxylcytosine, which are generated by TET (Ten-Eleven Translocation) enzymes during active DNA demethylation. ${ }^{26}$ However, when looking into other functions, TDG played a prominent role in oxidation and excision of $5 \mathrm{Mc}$ in DNA, thus controlling DNA demethylation. ${ }^{27,28}$ And the excessive demethylation is suspected to be in connection to cancer. Koslowski's report first revealed that hypoxia-inducible factor 1 alpha (HIF-1 alpha) showed a high level of expression in human cancers, and Tumor-associated $\mathrm{CpG}$ demethylation promoted positive autoregulation of HIF-1 alpha, thus resulting in the transactivation of the HIF-1 alpha target gene, which was induced by hypoxia, and it affected the growth of malignant cells. ${ }^{29}$ In addition, gene expression regulation is suggested to be correlated with TDG because it interacts with several transcription factors, chromatin-modifying enzymes and DNMTs. ${ }^{22,27}$ And the immoderate expression-induced excess cell proliferation may associate with cancer.

The OGG1 gene, which can express both DNA glycosylase and apurinic or apyrimidinic (AP) lyase, positions in chromosome $3 \mathrm{p} 25 .^{30}$ However, there could be other functions that may be detrimental. Another protein, PARP-1 (Poly [ADP-ribose] polymerase 1), which has a synergistic effect with OGG1, acting as a molecular sensor of broken DNA or some damage like oxidatively modified 

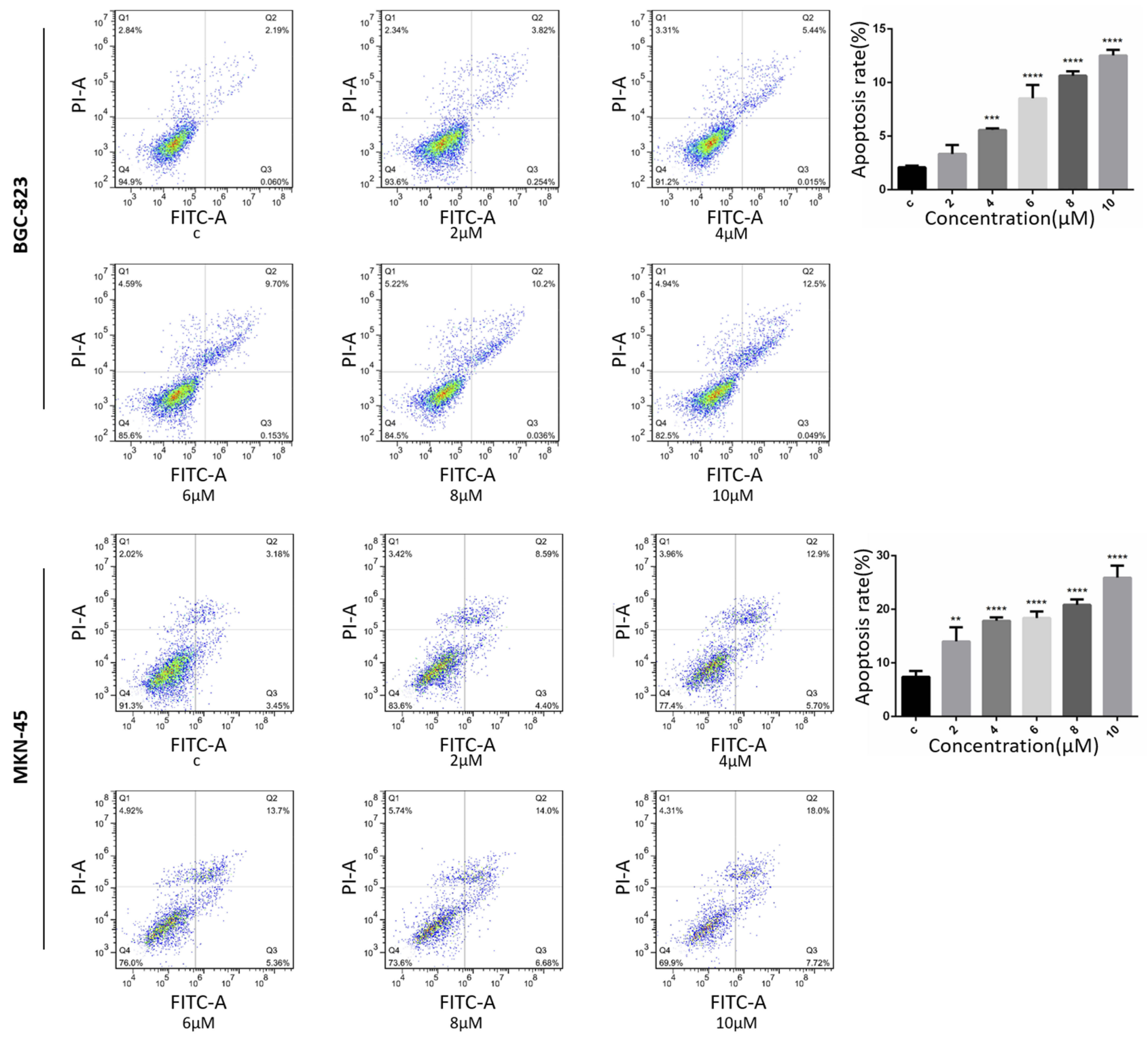

Figure 9 VE-822 enhances apoptosis in BGC-823 and MKN-45 cells of gastric cancer. Flow cytometry for apoptosis [apoptosis ratio was calculated as (Q2+Q3)/(QI+Q2 $+\mathrm{Q} 3+\mathrm{Q} 4)]$ of BGC-823 and MKN-45 cells incubated with $2 \mu \mathrm{M}, 4 \mu \mathrm{M}, 6 \mu \mathrm{M}, 8 \mu \mathrm{M}, 10 \mu \mathrm{M} \mathrm{VE}-822$ or an equal volume of DMEM medium for 48 hrs. VE-822 significantly promoted apoptosis in BGC-823 and MKN-45 cells of gastric cancer, and the apoptosis induced by VE-822 is concentration-dependent. *Data are presented as mean \pm SD, $\mathrm{N}=3$; **P<0.0I; $* * * P<0.001$; **** $P<0.000 \mathrm{I}$, compared with control.

nucleotides, regulates BER. ${ }^{31-33}$ Furthermore, both enzymes may regulate the expression of critical genes, thus contributing to cancer progression. c-MYC (MYC proto-oncogene) may promote the expression of the cMYC gene by converting the human c-MYC promoter's guanine-quadruplex structure into B-DNA, thereby promoting the proximity of the transcription factor to the promoter. ${ }^{34}$ And, OGG1 promotes transcription of genes which was controlled by c-MYC. ${ }^{35}$ Eid suggested that there is a significant positive association between the amplification of c-MYC and advanced cervix cancer grading; furthermore, it could be detected in the early stages; thus, c-MYC helped in the diagnosis and prognosis. $^{36}$ Other studies showed that adenoma-carcinoma pathway colon lesions usually linked with OGG1 genes' overexpression, and that this phenomenon is more significant in severe ones. ${ }^{37}$ This result also implies that the high expression of OGG1 indicates a worse prognosis.

Our result showed that MUTYH was significantly correlated to a worse OS in all GC patients and intestinal-type patients by Lauren classification. MUTYH can initiate correction of replication errors by acting at replication 


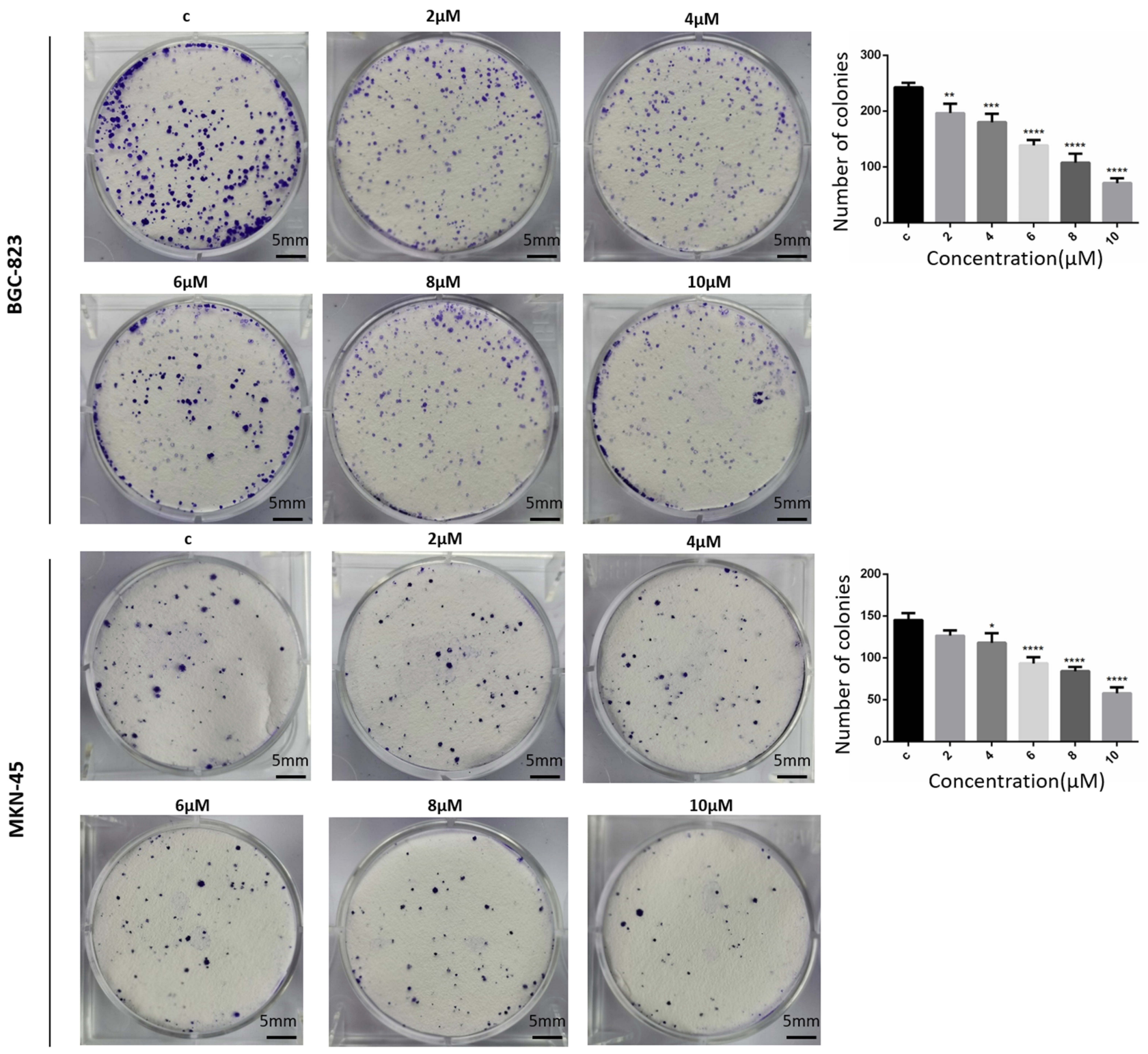

Figure 10 VE-822 inhibit BGC-823 and MKN-45 cells of gastric cancer proliferation. Colony formation assay following BGC-823 and MKN-45 cells incubated with $2 \mu \mathrm{M}$, $4 \mu \mathrm{M}, 6 \mu \mathrm{M}, 8 \mu \mathrm{M}, 10 \mu \mathrm{M}$ VE-822 or an equal volume of DMEM medium for 48 hrs. VE-822 significantly inhibited proliferation in BGC-823 and MKN-45 cells of gastric cancer, and the proliferation inhibited by $\mathrm{VE}-822$ is concentration-dependent. Scale bar $=5 \mathrm{~mm}$. *Data are presented as mean $\pm \mathrm{SD}, \mathrm{N}=3$; $* P<0.05$; $* * P<0.0 \mathrm{I}$; $* * * P<0.00 \mathrm{I}$; $* * * * P<0.0001$, compared with control.

forks. ${ }^{38}$ And MUTYH is usually considered to have the ability of repairing DNA 8-oxoG, but despite the former advantage, MUTYH could also contribute to therapeutic toxicity. Both DNA 6-TG and UVA, caused by therapeutic thiopurines, are cytotoxic and their interaction results in oxidative damage. DNA-protein crosslinks may cause DNA damage. The interactions of MUTYH with 28 parts of the replication systems may lead it to crosslinking to DNA-embedded 6-TG. ${ }^{39}$

The higher expression of the NEIL1 mRNA level is significantly associated with worse OS in all GC cancer patients. The NEIL1 DNA glycosylase can recognize oxidized bases and remove damage before the formation of the replication fork. ${ }^{40}$ Nevertheless, Shinmura suggested that among breast invasive carcinoma, a decline of NEIL1 expression predicted a poor survival outcome, but gastric cancer was not included. ${ }^{41}$

We also documented overexpression of the BER system in 5-FU-based adjuvant, which showed markedly unfavorable prognosis. The potential mechanisms of cell killing in 5-FU-mediated way are not clear, though it has been put into use for over 40 years. ${ }^{42}$ Some researchers indicated that 


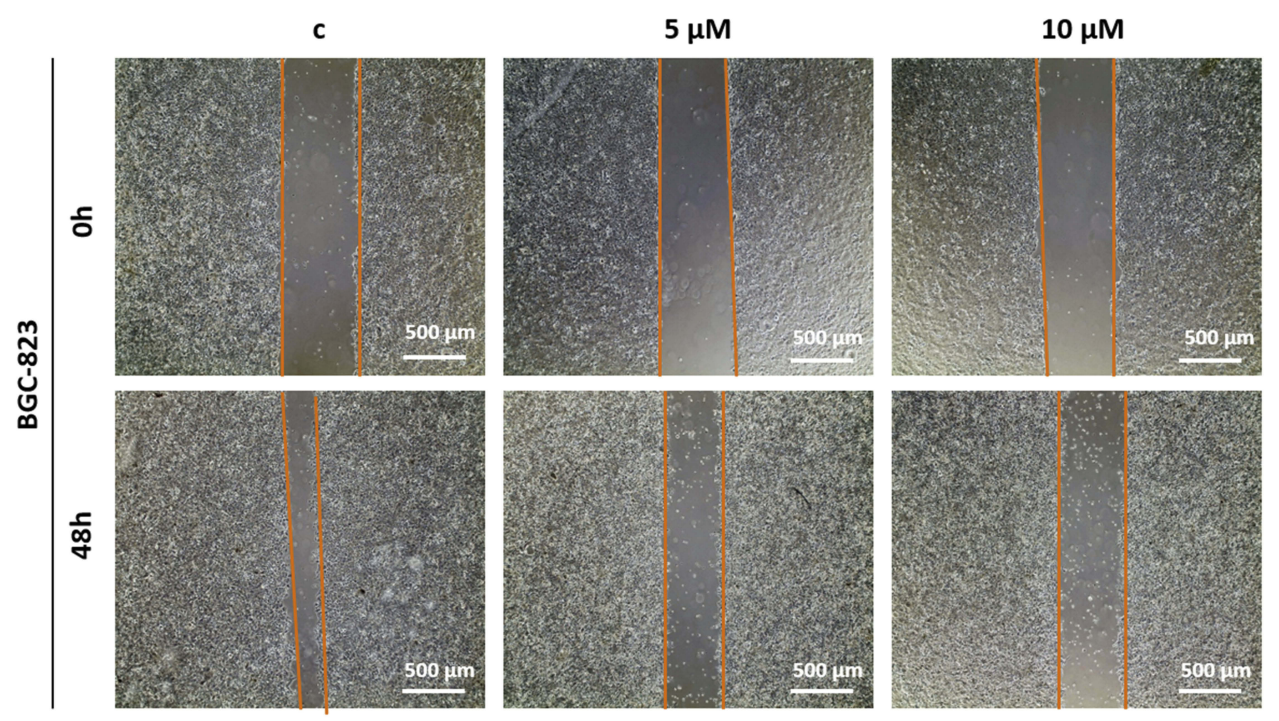

Figure I I VE-822 inhibit BGC-823 cells of gastric cancer migration. Migration following BGC-823 cells incubated with $5 \mu \mathrm{M}$, I0 $\mu$ M, VE-822 or an equal volume of DMEM medium for 48 hrs. VE-822 significantly inhibited migration in BGC-823 cells of gastric cancer. Scale bar $=500 \mu \mathrm{m}$.

A

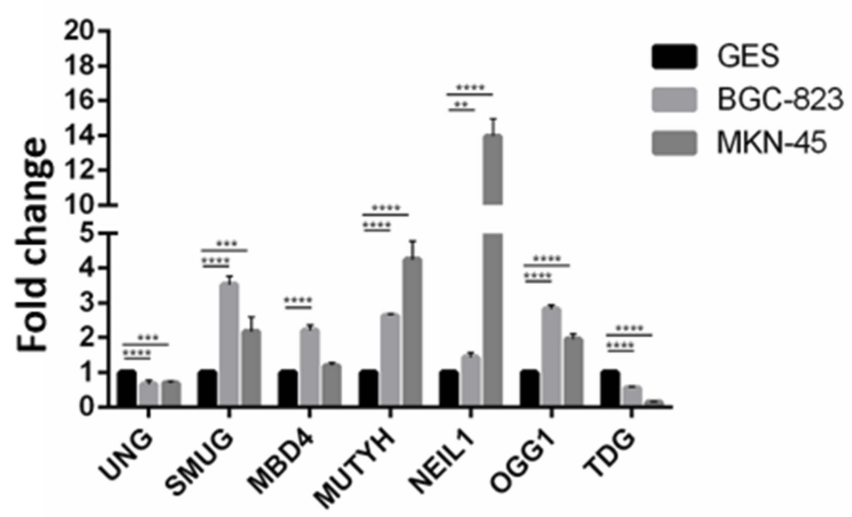

C

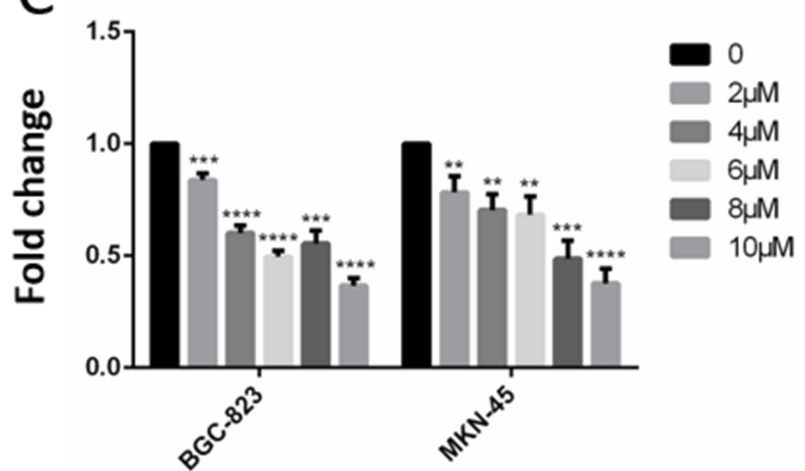

B
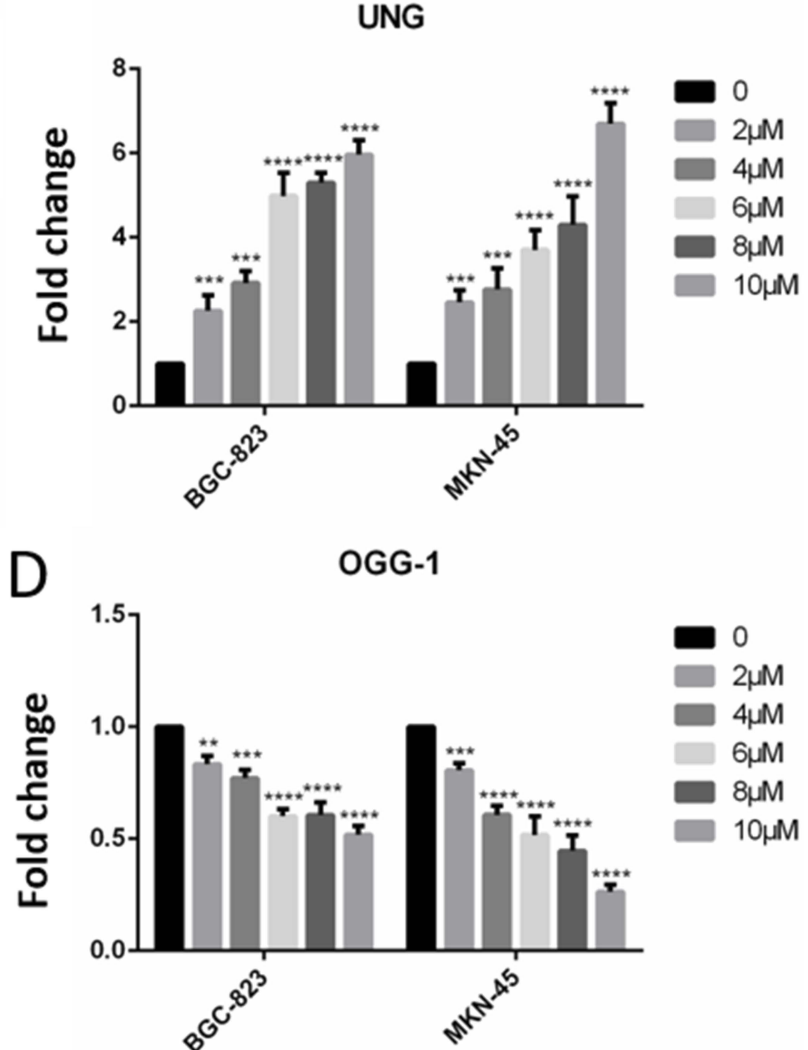

Figure 12 VE-822 inhibits proliferation and induces apoptosis of gastric cancer cells through influencing BER genes expression. (A) The difference expression of BER genes (UNG, SMUGI, MBD4, OGGI, MUTYH TDG and NEILI) in normal gastric cells (GES-I) and gastric cancer cells (BGC-832 and MKN-45). (B, C, D) The expression change of BER (UNG, MUTYH, OGG-I) system genes in the BGC-823 and MKN-45 cells of gastric cancer after treating with VE-822. *Data are presented as mean \pm SD, N=3; $* P<0.05 ; * * P<0.01 ; * * * P<0.001$; $* * * *<<0.0001$, compared with control.

BER may be the main repairment of 5 -FU in DNA. ${ }^{43}$ Furthermore, Pettersen's study indicated that this way may badly effect chemotherapy, and the uracil and 5-FU may induce "futile cycling" of uracil BER. ${ }^{43}$ During this cycling, some toxic products like single-strand breaks, double-strand breaks or basic sites may promote cell death. ${ }^{44}$ 
Furthermore, based on our prognostic function of BER system in GC patients, we show the potential role of VE-822 in gastric cancer therapy inhibiting gastric cancer growth by regulating the BER system. However, the detail regulation mechanism of the three valuable BER members in gastric cancer needs further determined. In future studies, gene regulation, especially overexpressed $\mathrm{UNG}$, is potentially helpful to understand the role of BER system-related DNA damage repair in gastric cancer.

\section{Conclusion}

In the present study, the prognostic value of 7 BER system members in gastric cancer was assessed based on the KM plotter database. High UNG expression was associated with high overall survival probability, whereas SMUG1, MBD4, TDG, OGG1, MUTYH and NEIL1 were related to low survival rate. Furthermore, we confirmed the importance of DNA damage repair in gastric cancer cells based on multiple cell proliferation, migration and apoptosis experiment and suggested the inhibition of gastric cancer via VE-822 may be regulated by UNG, OGG-1 and MUTYH. Our data are helpful to investigate the role of BER system in gastric cancer and provide novel perspectives to assess the prognostic value of BER in gastric cancer progression.

\section{Abbreviations}

5-FU, 5-Fluorouracil; 5Mc, 5-methylcytosine; 6-TG, 6-thioguanine; 8-oxoG, 8-oxoguanine; AP, apurinic or apyrimidinic; APE, AP-endonuclease; APOBEC3B, apolipoprotein B mRNA-editing enzyme catalytic subunit 3B; ATCC, American type culture collection; BER, base excision repair; CI, confidence interval; c-myc, MYC proto-oncogene; DMSO, dimethylsulfoxide; dU, deoxyuridine; dUTP, deoxyuridine triphosphate; GC, gastric cancer; FDR, false discovery rate; HER2, human epidermal growth factor receptor-2; HIF-1 $\alpha$, hypoxia-inducible factor $1 \alpha$; HR, hazard ratio; KM plotter, Kaplan-Meier plotter; MBD4, Methyl-CpG binding domain 4; MSP, macrophage stimulating protein; MUTYH, MutY DNA glycosylase; NEIL1, Nei like DNA glycosylase 1; OGG1, 8-oxoguanine DNA glycosylase; OS, overall survival; P, probability; PARP-1, Poly [ADP-ribose] polymerase 1; PBS, phosphate buffered saline; PI, propidium iodide; PI-3K, phosphatidylinositol 3 kinase; RON, recepteur D'origine nantais; ROS, reactive oxygen species; RTCA, real-time cellular analysis; RTPCR, reverse transcription-polymerase chain reaction; SNK, student-Newman Keuls tests; SMUG1, single- strand-selective monofunctional uracil-DNA glycosylase 1; TDG, thymine DNA glycosylase; TET, ten-eleven translocation; UNG, uracil-DNA glycosylase; UVA, ultraviolet A; VE-822, berzosertib.

\section{Disclosure}

All authors declare no conflicts of interest in this work.

\section{References}

1. Torre LA, Bray F, Siegel RL, Ferlay J, Lortet-Tieulent J, Jemal A. Global cancer statistics, 2012. CA Cancer J Clin. 2015;65(2):87-108.

2. Yang W, Raufi A, Klempner SJ. Targeted therapy for gastric cancer: molecular pathways and ongoing investigations. Biochim Biophys Acta. 2014;1846(1):232-237.

3. Oba K, Paoletti X, Bang YJ, et al. Role of chemotherapy for advanced/recurrent gastric cancer: an individual-patient-data metaanalysis. Eur J Cancer. 2013;49(7):1565-1577.

4. Maynard S, Schurman SH, Harboe C, de Souza-Pinto NC, Bohr VA. Base excision repair of oxidative DNA damage and association with cancer and aging. Carcinogenesis. 2009;30(1):2-10. doi:10.1093/car$\operatorname{cin} /$ bgn 250

5. Roos WP, Thomas AD, Kaina B. DNA damage and the balance between survival and death in cancer biology. Nat Rev Cancer. 2016;16(1):20-33. doi:10.1038/nrc.2015.2

6. Karahalil B, Bohr VA, Wilson DM 3rd. Impact of DNA polymorphisms in key DNA base excision repair proteins on cancer risk. Hum Exp Toxicol. 2012;31(10):981-1005. doi:10.1177/0960327112444476

7. Wang T, Xuan X, Li M, et al. Astragalus saponins affect proliferation, invasion and apoptosis of gastric cancer BGC-823 cells. Diagn Pathol. 2013;8:179. doi:10.1186/1746-1596-8-179

8. Liu J, Ma L, Xu J, et al. Spheroid body-forming cells in the human gastric cancer cell line MKN-45 possess cancer stem cell properties. Int J Oncol. 2013;42(2):453-459. doi:10.3892/ijo.2012.1720

9. Yang R, Lin Q, Gao HB, Zhang P. Stress-related hormone norepinephrine induces interleukin-6 expression in GES-1 cells. Braz J Med Biol Res. 2014;47(2):101-109.

10. Alsoe L, Sarno A, Carracedo S, et al. Uracil accumulation and mutagenesis dominated by cytosine deamination in $\mathrm{CpG}$ dinucleotides in mice lacking UNG and SMUG1. Sci Rep. 2017;7(1):7199. doi:10.1038/s41598-017-07314-5

11. Kemmerich K, Dingler FA, Rada C, Neuberger MS. Germline ablation of SMUG1 DNA glycosylase causes loss of 5-hydroxymethyluracil- and UNG-backup uracil-excision activities and increases cancer predisposition of Ung-/-Msh2-/- mice. Nucleic Acids Res. 2012;40 (13):6016-6025. doi:10.1093/nar/gks259

12. Yousif AS, Stanlie A, Begum NA, Honjo T. Opinion: uracil DNA glycosylase (UNG) plays distinct and non-canonical roles in somatic hypermutation and class switch recombination. Int Immunol. 2014;26 (10):575-578. doi:10.1093/intimm/dxu071

13. Vural S, Simon R, Krushkal J. Correlation of gene expression and associated mutation profiles of APOBEC3A, APOBEC3B, REV1, UNG, and FHIT with chemosensitivity of cancer cell lines to drug treatment. Hum Genomics. 2018;12(1):20. doi:10.1186/s40246-018$0150-x$

14. Swanton C, McGranahan N, Starrett GJ, Harris RS. APOBEC enzymes: mutagenic fuel for cancer evolution and heterogeneity. Cancer Discov. 2015;5(7):704-712. doi:10.1158/2159-8290.CD-150344

15. Zou J, Wang C, Ma X, Wang E, Peng G. APOBEC3B, a molecular driver of mutagenesis in human cancers. Cell Biosci. 2017;7:29. doi:10.1186/s13578-017-0156-4 
16. Middlebrooks CD, Banday AR, Matsuda K, et al. Association of germline variants in the APOBEC3 region with cancer risk and enrichment with APOBEC-signature mutations in tumors. Nat Genet. 2016;48(11):1330-1338. doi:10.1038/ng.3670

17. Zhang J, Wei W, Jin HC, Ying RC, Zhu AK, Zhang FJ. The roles of APOBEC3B in gastric cancer. Int $J$ Clin Exp Pathol. 2015;8 (5):5089-5096.

18. Girelli Zubani G, Zivojnovic M, De Smet A, et al. Pms2 and uracilDNA glycosylases act jointly in the mismatch repair pathway to generate Ig gene mutations at A-T base pairs. J Exp Med. 2017;214 (4):1169-1180. doi:10.1084/jem.20161576

19. Di Noia JM, Rada C, Neuberger MS. SMUG1 is able to excise uracil from immunoglobulin genes: insight into mutation versus repair. EMBO J. 2006;25(3):585-595. doi:10.1038/sj.emboj.7600939

20. Nagaria P, Svilar D, Brown AR, Wang XH, Sobol RW, Wyatt MD. SMUG1 but not UNG DNA glycosylase contributes to the cellular response to recovery from 5-fluorouracil induced replication stress. Mutat Res. 2013;743-744:26-32. doi:10.1016/j.mrfmmm.2012.12.001

21. Laget S, Miotto B, Chin HG, et al. MBD4 cooperates with DNMT1 to mediate methyl-DNA repression and protects mammalian cells from oxidative stress. Epigenetics. 2014;9(4):546-556. doi:10.4161/ epi. 27695

22. Chen D, Lucey MJ, Phoenix F, et al. T:G mismatch-specific thymineDNA glycosylase potentiates transcription of estrogen-regulated genes through direct interaction with estrogen receptor alpha. J Biol Chem. 2003;278(40):38586-38592. doi:10.1074/jbc.M304286200

23. Yamada T, Koyama T, Ohwada S, et al. Frameshift mutations in the MBD4/MED1 gene in primary gastric cancer with high-frequency microsatellite instability. Cancer Lett. 2002;181(1):115-120. doi:10.1016/S0304-3835(02)00043-5

24. Cunha S, Lin YC, Goossen EA, et al. The RON receptor tyrosine kinase promotes metastasis by triggering MBD4-dependent DNA methylation reprogramming. Cell Rep. 2014;6(1):141-154. doi:10.1016/j.celrep.2013.12.010

25. Xiong XD, Luo XP, Liu X, et al. The MBD4 Glu346Lys polymorphism is associated with the risk of cervical cancer in a Chinese population. Int J Gynecol Cancer. 2012;22(9):1552-1556.

26. $\mathrm{Xu} \mathrm{J}$, Cortellino $\mathrm{S}$, Tricarico $\mathrm{R}$, et al. Thymine DNA Glycosylase (TDG) is involved in the pathogenesis of intestinal tumors with reduced APC expression. Oncotarget. 2017;8(52):89988-89997.

27. Dalton SR, Bellacosa A. DNA demethylation by TDG. Epigenomics. 2012;4(4):459-467. doi:10.2217/epi.12.36

28. Weber AR, Krawczyk C, Robertson AB, et al. Biochemical reconstitution of TET1-TDG-BER-dependent active DNA demethylation reveals a highly coordinated mechanism. Nat Commun. 2016;7:10806. doi:10.1038/ncomms10806

29. Koslowski M, Luxemburger U, Tureci O, Sahin U. Tumor-associated $\mathrm{CpG}$ demethylation augments hypoxia-induced effects by positive autoregulation of HIF-1alpha. Oncogene. 2011;30(7):876-882. doi:10.1038/onc.2010.481
30. Zhou PT, Li B, Ji J, Wang MM, Gao CF. A systematic review and meta-analysis of the association between OGG1 Ser326Cys polymorphism and cancers. Med Oncol. 2015;32(2):472. doi:10.1007/ s12032-014-0472-z

31. Hegde ML, Hazra TK, Mitra S. Early steps in the DNA base excision/single-strand interruption repair pathway in mammalian cells. Cell Res. 2008;18(1):27-47. doi:10.1038/cr.2008.8

32. Flohr C, Burkle A, Radicella JP, Epe B. Poly(ADP-ribosyl)ation accelerates DNA repair in a pathway dependent on Cockayne syndrome B protein. Nucleic Acids Res. 2003;31(18):5332-5337. doi:10.1093/nar/gkg715

33. Noren Hooten N, Kompaniez K, Barnes J, Lohani A, Evans MK. Poly(ADP-ribose) polymerase 1 (PARP-1) binds to 8-oxoguanineDNA glycosylase (OGG1). J Biol Chem. 2011;286(52):4467944690. doi:10.1074/jbc.M111.255869

34. Fekete A, Kenesi E, Hunyadi-Gulyas E, et al. The guanine-quadruplex structure in the human c-myc gene's promoter is converted into B-DNA form by the human poly(ADP-ribose)polymerase-1. PLoS One. 2012;7(8):e42690. doi:10.1371/journal.pone.0042690

35. Dziaman T, Ludwiczak H, Ciesla JM, et al. PARP-1 expression is increased in colon adenoma and carcinoma and correlates with OGG1. PLoS One. 2014;9(12):e115558. doi:10.1371/journal.pone.0115558

36. Eid MM, Nossair HM, Ismael MT, Amira G, Hosney MM, Abdul Rahman R. Clinical significance of hTERC and C-Myc genes amplification in a group of Egyptian patients with cancer cervix. Gulf J Oncolog. 2011;10:18-26.

37. Saebo M, Skjelbred CF, Nexo BA, et al. Increased mRNA expression levels of ERCC1, OGG1 and RAI in colorectal adenomas and carcinomas. BMC Cancer. 2006;6:208. doi:10.1186/1471-2407-6-208

38. Mazzei F, Viel A, Bignami M. Role of MUTYH in human cancer. Mutat Res. 2013;743-744:33-43. doi:10.1016/j.mrfmmm.2013.03.003

39. Grasso F, Ruggieri V, De Luca G, et al. MUTYH mediates the toxicity of combined DNA 6-thioguanine and UVA radiation. Oncotarget. 2015;6(10):7481-7492. doi:10.18632/oncotarget.v6i10

40. Galick HA, Marsden CG, Kathe S, et al. The NEIL1 G83D germline DNA glycosylase variant induces genomic instability and cellular transformation. Oncotarget. 2017;8(49):85883-85895. doi:10.18632/ oncotarget.20716

41. Shinmura K, Kato H, Kawanishi Y, et al. Abnormal expressions of DNA glycosylase genes NEIL1, NEIL2, and NEIL3 are associated with somatic mutation loads in human cancer. Oxid Med Cell Longev. 2016;2016:1546392. doi:10.1155/2016/1546392

42. de Bono JS, Twelves CJ. The oral fluorinated pyrimidines. Invest New Drugs. 2001;19(1):41-59. doi:10.1023/A:1006404701008

43. Pettersen HS, Visnes T, Vagbo CB, et al. UNG-initiated base excision repair is the major repair route for 5-fluorouracil in DNA, but 5fluorouracil cytotoxicity depends mainly on RNA incorporation. Nucleic Acids Res. 2011;39(19):8430-8444. doi:10.1093/nar/gkr563

44. Tinkelenberg BA, Hansbury MJ, Ladner RD. dUTPase and uracilDNA glycosylase are central modulators of antifolate toxicity in Saccharomyces cerevisiae. Cancer Res. 2002;62(17):4909-4915.
Cancer Management and Research is an international, peer-reviewed open access journal focusing on cancer research and the optimal use of preventative and integrated treatment interventions to achieve improved outcomes, enhanced survival and quality of life for the cancer patient.
The manuscript management system is completely online and includes a very quick and fair peer-review system, which is all easy to use. Visit http://www.dovepress.com/testimonials.php to read real quotes from published authors. 